\title{
Nicotinic Enhancement of the Noradrenergic Inhibition of Sleep-Promoting Neurons in the Ventrolateral Preoptic Area
}

\author{
Benoît Saint-Mleux, ${ }^{1 *}$ Emmanuel Eggermann, ${ }^{1 *}$ Arnaud Bisetti, ${ }^{1}$ Laurence Bayer, ${ }^{1}$ Danièle Machard, ${ }^{1}$ \\ Barbara E. Jones, ${ }^{2}$ Michel Mühlethaler, ${ }^{1}$ and Mauro Serafin ${ }^{1}$ \\ ${ }^{1}$ Département de Physiologie, Centre Médical Universitaire, 1211 Geneva 4, Switzerland, and 2Department of Neurology and Neurosurgery, McGill \\ University, Montreal Neurological Institute, Montreal, Quebec, Canada H3A 2B4
}

According to multiple lines of evidence, neurons in the ventrolateral preoptic area (VLPO) that contain GABA promote sleep by inhibiting neurons of the arousal systems. Reciprocally, transmitters used by these systems, including acetylcholine (ACh) and noradrenaline (NA), exert an inhibitory action on the VLPO neurons. Because nicotine, an agonist of $\mathrm{ACh}$, acts as a potent stimulant, we queried whether it might participate in the cholinergic inhibition of these sleep-promoting cells. Indeed, we found that ACh inhibits the VLPO neurons through a nicotinic, as well as a muscarinic, action. As evident in the presence of atropine, the non-muscarinic component was mimicked by epibatidine, a nonselective nicotinic $\mathrm{ACh}$ receptor (nAChR) agonist and was blocked by dihydro- $\beta$-erythroidine, a nonselective nAChR antagonist. It was not, however, blocked by methyllycaconitine, a selective antagonist of the $\alpha 7$ subtype, indicating that the action was mediated by non- $\alpha 7 \mathrm{nAChRs}$. The nicotinic inhibition was attributed to a presynaptic facilitation of NA release because it persisted in the presence of tetrodotoxin and was blocked by yohimbine and RS 79948, which are both selective antagonists of $\alpha 2$ adrenergic receptors. Sleep-promoting VLPO neurons are thus dually inhibited by ACh through a muscarinic postsynaptic action and a nicotinic presynaptic action on noradrenergic terminals. Such dual complementary actions allow ACh and nicotine to enhance wakefulness by inhibiting sleep-promoting systems while facilitating other wake-promoting systems.

Key words: arousal; rat; sleep; smoking; vigilance; wakefulness

\section{Introduction}

In recent years, neurons in the ventrolateral preoptic area (VLPO) have been postulated to play a significant role in promoting sleep (for recent sleep reviews, see Jones, 2000; Saper et al., 2001; Szymusiak et al., 2001; Mignot et al., 2002; Pace-Schott and Hobson, 2002). The preoptic region has long been known to be important for sleep because lesions of the basal forebrain/preoptic area, whether resulting from viral encephalitis in humans (Von Economo, 1931) or from experimental lesions in rats or cats (Nauta, 1946; McGinty and Sterman, 1968), were found to be associated with severe disruption of sleep. More recently, lesions restricted to the VLPO were also shown to diminish sleep (Lu et al., 2000). Experiments using c-Fos immunohistochemistry (Sherin et al., 1996, 1998) and unit recordings (Szymusiak et al., 1998) have shown that most VLPO neurons are more active during sleep than during wakefulness. Because many VLPO neurons contain GABA and project to multiple monoaminergic and cholinergic cell groups (for review, see Saper et al., 2001), they would have the capacity to inhibit the major arousal systems of the brain

\footnotetext{
Received June 30, 2003; revised 0ct. 14, 2003; accepted 0ct. 29, 2003.

This study was supported by grants from the Swiss Fonds National, the Novartis, OTT, de Reuter, and Schmidheiny Foundations (M.M., M.S.), and the Canadian Medical Research Council (B.E.J.).

${ }^{*}$ B.S.-M. and E.E. contributed equally to this work.

Correspondence should be addressed to Dr. Mauro Serafin, Centre Médical Universitaire, Département de Physiologie, 1 Rue Michel-Servet, 1211 Geneva 4, Switzerland. E-mail: mauro.serafin@medecine.unige.ch. DOI:10.1523/JNEUROSCI.0232-03.2004

Copyright $\odot 2004$ Society for Neuroscience $\quad$ 0270-6474/04/240063-05\$15.00/0
}

and thus promote sleep when active. We showed recently in vitro that neurotransmitters of the activating systems, most notably noradrenaline (NA) and acetylcholine (ACh), inhibit GABAergic VLPO neurons in a manner such as to suggest a reciprocal interaction of the wake-promoting and sleep-promoting neurons across the sleep-waking cycle (Gallopin et al., 2000).

It is well known that stimulants act by enhancing or mimicking the actions of neurotransmitters of the arousal systems (Koelega, 1993; Jones, 2003). By enhancing the release of NA, amphetamine would also act by inhibiting the sleep-promoting neurons in the VLPO. We queried here whether nicotine, another well known stimulant, would participate in the documented cholinergic inhibition of VLPO neurons (Gallopin et al., 2000). To test this possibility, we examined the effect of ACh and nicotinic agonists in the presence and absence of muscarinic blockers on VLPO neurons in rat brain slices.

\section{Materials and Methods}

Electrophysiological recordings. Brain slices were obtained from young rats (15-20 d), reared at the animal facility of the Geneva Medical Centre, and treated according to the regulations of the Swiss Federal Veterinary Office. Before use, slices (300- $\mu \mathrm{m}$-thick) containing the VLPO (Sherin et al., 1996; Lu et al., 2002) were incubated at room temperature in artificial CSF (ACSF) that contained the following (in mM): $130 \mathrm{NaCl}, 5 \mathrm{KCl}, 1.25$ $\mathrm{KH}_{2} \mathrm{PO}_{4}, 1.3 \mathrm{MgSO}_{4}, 20 \mathrm{NaHCO}_{3}, 10$ glucose, and $2.4 \mathrm{CaCl}_{2}$ (bubbled with a mixture of $95 \% \mathrm{O}_{2}-5 \% \mathrm{CO}_{2}$ ). Individual slices were transferred to a thermoregulated $\left(32^{\circ} \mathrm{C}\right)$ chamber on a Zeiss (Oberkochen, Germany) Axioskop equipped with an infrared camera (Dodt and Zieglgansberger, 1994). Slices were maintained immersed and continuously superfused at 
$4-5 \mathrm{ml} / \mathrm{min}$. Patch electrodes were pulled on a DMZ universal puller (Zeitz-Instrumente, Augsburg, Germany) from borosilicate glass capillaries (GC150F-10; Clark Electromedical Instruments, Pangbourne, UK). For extracellular recordings in the loose-attached configuration, patch electrodes (5-7 M $\Omega$ ) were filled with ACSF. For whole-cell recordings, the pipettes $(8-10 \mathrm{M} \Omega$ ) contained the following solution (in $\mathrm{mM}$ ): $126 \mathrm{KMeSO}_{4}, 8$ phosphocreatine, $4 \mathrm{KCl}, 5 \mathrm{MgCl}_{2}, 10 \mathrm{HEPES}, 3 \mathrm{Na}_{2} \mathrm{ATP}$, $0.1 \mathrm{GTP}$, and 0.1 BAPTA, pH 7.4 (290-310 mOsm; estimated junction potential, $-9.5 \mathrm{mV}$ ). Cells were identified using infrared differential interference contrast video microscopy on an upright Zeiss microsope. Recordings were made in the whole-cell configuration using the Axopatch 200 B (Axon Instruments, Foster City, CA) in the current-clamp mode. Synaptic blockade was realized by lowering calcium and increasing magnesium $\left(10 \mathrm{~mm} \mathrm{Mg}^{2+}-0.1 \mathrm{mMCa}^{2+}\right)$.

Iontophoresis. Theta-tube pipettes (TGC 150F-10; $2 \mu \mathrm{m}$ tip diameter; 10-12 $\mathrm{M} \Omega$ single-barrel resistance; Clark Electromedical Instruments) were used for iontophoresis. One barrel contained ACh (100 mM, pH 6) diluted in ACSF, and the other one contained ACSF alone. Pipettes were placed 20-50 $\mu \mathrm{m}$ away from the recorded cells. A retention $(-)-$ ejection $(+)$ current of 50-100 nA (Axoclamp 2B; Axon Instruments) was applied between the drug- and the saline-containing barrels to, respectively, retain and deliver ACh. In some occasions, regular pipettes (GC 150F-10; $2 \mu \mathrm{m}$ tip diameter; 5-7 M ; Clark Electromedical Instruments) grounded to the bath and filled with ACh were used, after verification was made that current injection with pipettes containing ACSF instead of ACh had no effect per se on the firing rate of recorded cells $(n=$ 3 of 3). The duration of ACh applications was $2-10 \mathrm{sec}$, and the delay between two successive applications was $8-15 \mathrm{~min}$. The percentage of recovery from inhibition was $65.4 \pm 4.2 \%$ at $8 \mathrm{~min}$ and reached $100 \pm$ $0 \%$ at $15 \mathrm{~min}(n=5)$. In all experiments in which the nicotinedependent effects of ACh were tested, atropine was present in the ACSF at $5 \mu \mathrm{M}$.

Drugs. The substances used in the present study were the following: noradrenaline; yohimbine and RS 79948 (two selective antagonists of $\alpha 2$ noradrenergic receptors); ACh; muscarine; nicotine; epibatidine [a nonselective nicotinic ACh receptor (nAChR) agonist]; atropine sulfate (muscarinic blocker); methyllycaconitine (MLA) (a selective antagonist of $\alpha 7 \mathrm{nAChRs}$ ); dihydro- $\beta$-erythroidine (DH $\beta \mathrm{E}$ ) (a nonselective antagonist of nAChRs); bicuculline and saclofen (selective $\mathrm{GABA}_{\mathrm{A}}$ and $\mathrm{GABA}_{\mathrm{B}}$ antagonists); and tetrodotoxin (TTX) (Latoxan, Valence, France). With the exception of saclofen, bicuculline, and RS 79949, which were obtained from Tocris Cookson (Ballwin, MO), all other substances were obtained from Sigma (St. Louis, MO). Drugs were diluted in ACSF and applied in the bath at a known concentration. Antagonists were preapplied for $5 \mathrm{~min}$.

\section{Results}

VLPO neurons are inhibited through activation of both muscarinic and nicotinic receptors

Under infrared video microscopic guidance, extracellular looseattached patch recordings were obtained from neurons located in the central core of the VLPO cell cluster (Fig. $1 A$, inset), in which sleep-active cells were originally identified (Sherin et al., 1996). Cells were selected as putatively sleep-promoting according to previously established criteria (Gallopin et al., 2000). First, they were tripolar in shape (Fig. $1 A$, inset, in which two of three proximal dendrites of the cell are visible), and second, they were inhibited by NA $(5-10 \mu \mathrm{M})$ (Fig. $1 B)$.

Brief bath applications of $1 \mathrm{~mm}$ ACh inhibited all VLPO neurons $(n=3$ of 3 ) (Fig. $1 C$ ) that were inhibited by NA. In the presence of atropine at $5 \mu \mathrm{M}$, the response to ACh was reduced $(n=2$ of 2$)$ (Fig. $1 D)$, indicating that muscarinic receptors are partly responsible for the inhibitory effect. Indeed, muscarine (1 $\mu \mathrm{M})$ (Fig. $1 E$ ) potently inhibited VLPO neurons ( $n=15$ of 15$)$, an effect that was completely abolished by $5 \mu \mathrm{M}$ atropine $(n=9$ of 9; data not shown). Because the inhibitory effect of muscarine persisted in a $10 \mathrm{mM} \mathrm{Mg}^{2+}-0.1 \mathrm{mMCa}^{2+} \operatorname{ACSF}(n=3$ of 3 ) (Fig.
A
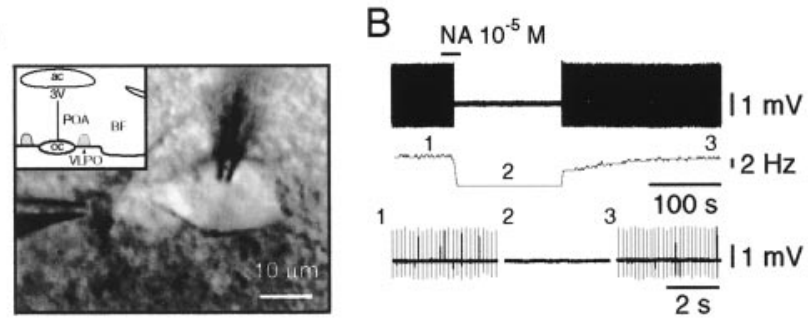

C

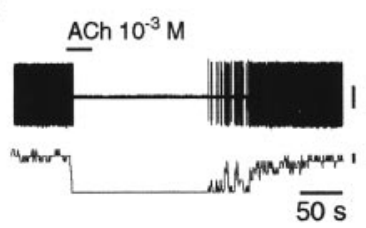

E

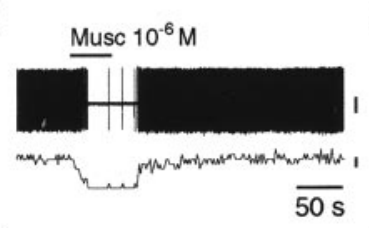

G
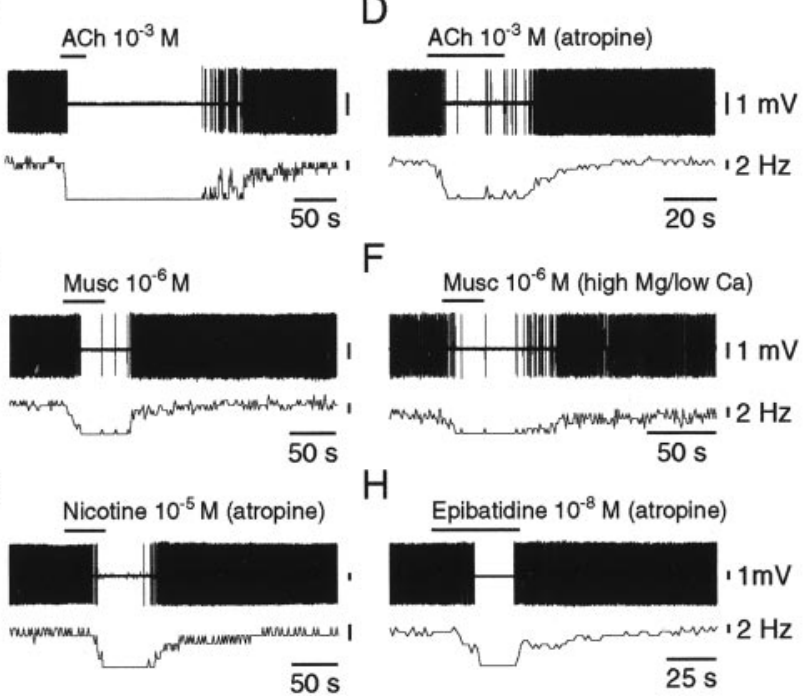

F

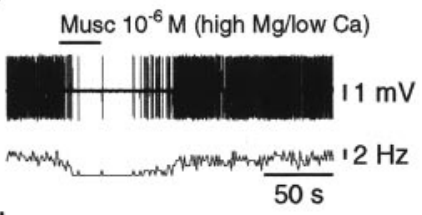

H

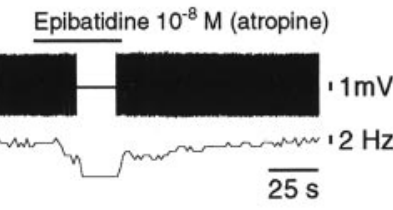

Figure 1. Identified VLPO neurons are inhibited by both muscarinic and nicotinic agonists. $A$, $B$, Characterization of a neuron located in the VLPO by its complete inhibition by bath-applied NA. C, D, Effects of ACh application in control ACSF or in the presence of atropine. E, F, Effect of muscarine in control ACSF or in a condition of synaptic blockade by a high $\mathrm{Mg}^{2+}-\mathrm{low} \mathrm{Ca}^{2+}$ ACSF. G, Effect of nicotine. $H$, Effect of epibatidine. 3V, Third ventricle; ac, anterior commissure; $\mathrm{BF}$, basal forebrain; $0 \mathrm{C}$, optic chiasm; POA, preoptic area.

$1 F)$, it must depend on muscarinic receptors located postsynaptically on the VLPO neurons.

The persistence of a residual inhibitory response to ACh in the presence of atropine (Fig. 1D) suggested that cholinergic receptors other than the muscarinic receptors are also involved in the inhibition of VLPO neurons by ACh. To test the possibility that nicotinic receptors could be involved, bath applications of nicotine were first used. These applications resulted in a potent inhibition (Fig. $1 G$ ) of VLPO cell discharge ( $n=9$ of 12 at $10 \mu \mathrm{M} ; n=$ 3 of 3 at $100 \mu \mathrm{M})$. Similarly, a nonselective nicotinic agonist, epibatidine, also produced a rapid and complete inhibition of VLPO neurons ( $n=3$ of 3 at $10 \mathrm{~nm}$ ) (Fig. $1 H$ ).

To investigate further the nature of the nicotinic inhibition of VLPO neurons, local iontophoretic applications of ACh were performed while in the presence of atropine. As illustrated in the rate-meter recording of Figure $2 \mathrm{~A}$, repetitive applications of $\mathrm{ACh}$ in the absence of atropine elicited inhibitions of constant strength (compare applications 1 and 2, top trace; illustrated in bottom left insets), presumably reflecting the absence of desensitization of the muscarinic postsynaptic component of the response. In contrast, in the presence of $5 \mu \mathrm{M}$ atropine (Fig. $2 \mathrm{~A}$, applications 3-8 and selected respective insets), the response to ACh showed rapid and prolonged desensitization (compare applications 3 and 4 ), necessitating intervals of several minutes between applications (as in between applications 7 and 8) to allow for recovery. Using this approach, the nature of the nicotinic receptor involved in the inhibitory response of VLPO neurons was further investigated. We found that the selective $\alpha 7$ antagonist MLA (10 nM) 
A

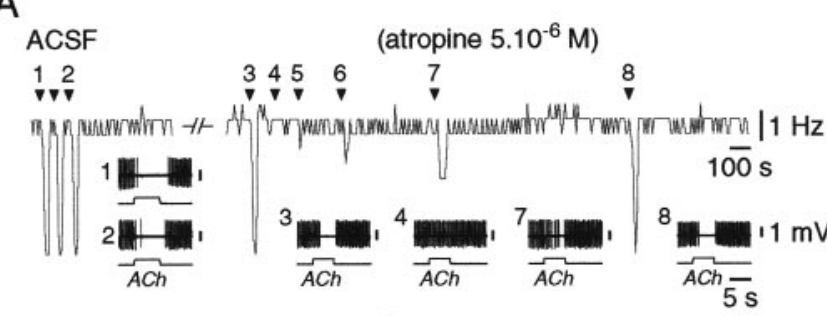

B

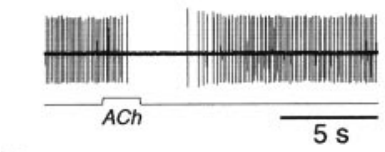

D

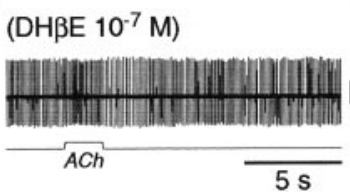

C

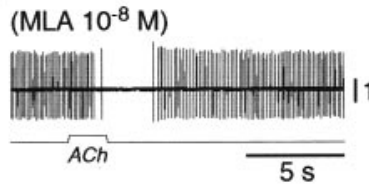

E

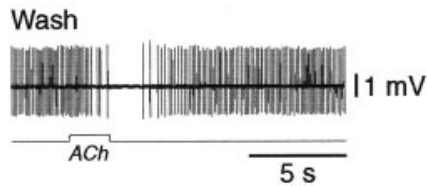

Figure 2. Characterization of the receptor implicated in the nicotinic inhibition of VLPO neurons. $A$, Rate-meter recording of the response of a neuron to repeated applications of $A C h$ in either a control ACSF or the presence of atropine. Timing of ACh applications is identified by black triangles and numbers (from 1 to 8 ). Numbered insets demonstrate the effects of some of the $A C h$ applications. $B-E$, Effect of $A C h$ applications (always in the presence of atropine) in control condition $(B)$ or in the presence of $\mathrm{MLA}(C, \mathrm{DH} \beta \mathrm{E}(D)$, and after $\mathrm{DH} \beta \mathrm{E}$ washout $(E)$.

was unable ( $n=4$ of 4 ) (Fig. $2 C$ ) to block the inhibition induced by the application of ACh in the presence of $5 \mu \mathrm{M}$ atropine (Fig. $2 B)$. In contrast, $\mathrm{DH} \beta \mathrm{E}(100 \mathrm{nM})$, a nonselective antagonist of nicotinic receptors, completely abolished $(n=4$ of 5$)$ the ACh effect (Fig. $2 D$ ) in a reversible manner (Fig. 2E). These results suggest that the cholinergic inhibition of VLPO neurons by ACh in the presence of atropine depends entirely on non- $\alpha 7$ nicotinic receptors.

\section{The nicotinic inhibition of VLPO neurons depends on the presynaptic release of NA}

We then tested whether the nicotinic effect could persist in conditions in which synaptic transmission was blocked by an ACSF containing $10 \mathrm{~mm} \mathrm{Mg}{ }^{2+}$ and $0.1 \mathrm{mM} \mathrm{Ca}^{2+}$. As illustrated in Figure $3 A$, the inhibition of VLPO neurons by ACh in the presence of atropine was completely and reversibly abolished in that condition ( $n=3$ of 3 ), indicating that it was indirect. Given the strength of the inhibition, it could be mediated through the presynaptic release of either GABA or NA, both of which are known to inhibit VLPO neurons (Eggermann et al., 2000; Gallopin et al., 2000). Selective antagonists of either $\mathrm{GABA}_{\mathrm{A}}$ receptors (bicuculline; $50 \mu \mathrm{M} ; n=3$ of 3 ) (Fig. $3 B$ ) or $\mathrm{GABA}_{\mathrm{B}}$ receptors (saclofen; $250 \mu \mathrm{M} ; n=4$ of 4 ) (Fig. 3C) did not alter the inhibition by ACh in the presence of atropine. In contrast, selective antagonists of the noradrenergic $\alpha 2$ receptor yohimbine ( $2 \mu \mathrm{M} ; n=7$ of 7 ) (Fig. $3 D$ ) and RS $79948(0.1-1 \mu \mathrm{M} ; n=4$ of 4 ) (Fig. 3E) completely abolished the nicotinic inhibition. Both compounds also completely abolished the inhibition of VLPO neurons by bathapplied NA ( $n=5$ of 5 for yohimbine; $n=2$ of 2 for RS 79948; data not shown).

To determine whether the mechanism of nicotinic facilitation of NA release was located on the terminals of noradrenergic fibers within the VLPO, we turned to whole-cell recordings. For that purpose, neurons were first recorded extracellularly and tested for their inhibitory response to NA by bath application (Fig. 4A,
A

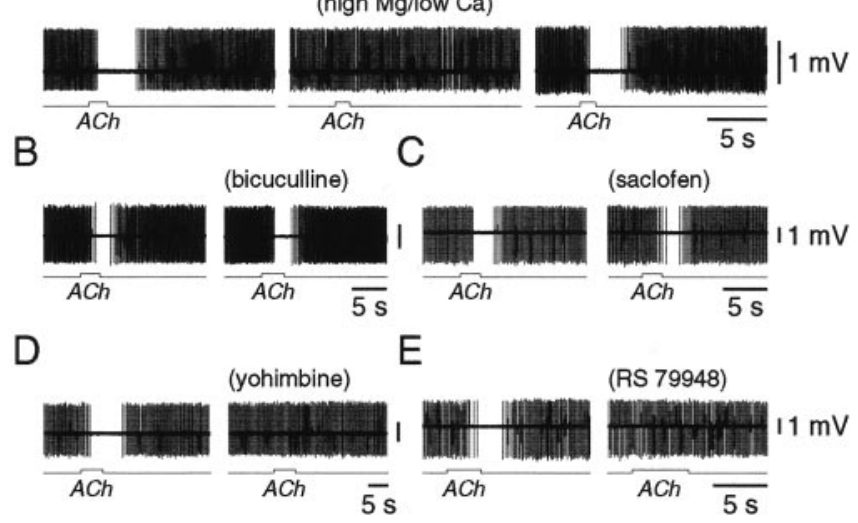

Figure 3. The nicotinic inhibition of VLPO neurons is abolished by either synaptic transmission blockade or $\alpha 2$ noradrenergic antagonists. A, Application of ACh in the presence of atropine in a control ACSF (left panel), followed by application of ACh in a high $\mathrm{Mg}^{2+}-$ low $\mathrm{Ca}^{2+}$ ACSF that abolished the response (middle panel). Right panel shows recovery of response after return to a control ACSF. $B, C$, Inhibitory action of ACh (left panels) is not blocked in the presence of either $\mathrm{GABA}_{A}$ (bicuculline; right panel in $B$ ) or $\mathrm{GABA}_{B}$ (saclofen; right panel in $C$ ) selective antagonists. $D, E$, Inhibitory action of ACh (left panels) is abolished by the $\alpha 2$ noradrenergic selective antagonists yohimbine (right panel in D) and RS 79948 (right panel in E).
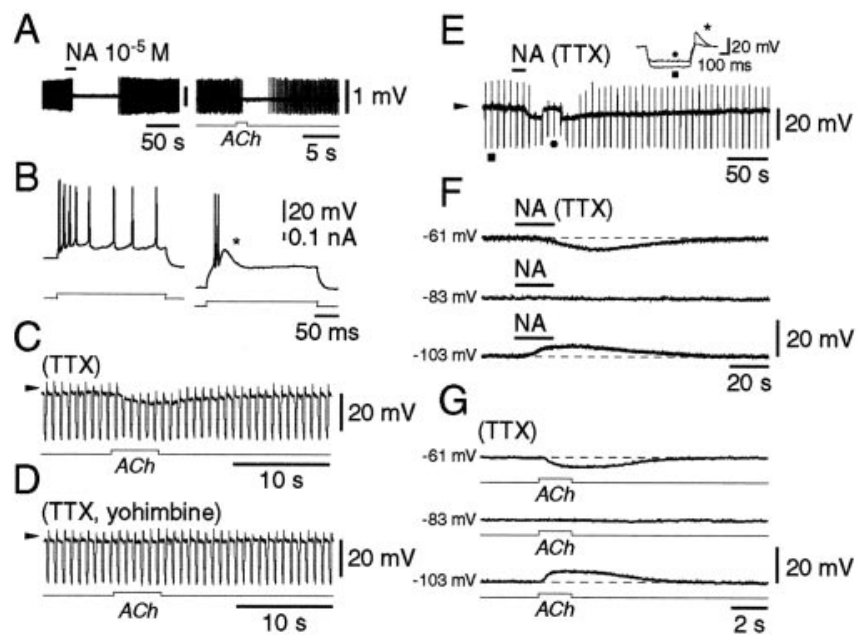

Figure 4. The nicotinic inhibition of VLPO neurons results from a presynaptic facilitation of NA release associated with an increase in a potassium conductance. $A, B$, Characterization of a VLPO neuron by its complete inhibition with bath application of NA in extracellular recordings (left panel in $A$ ) as well as its inhibitory response to $\mathrm{ACh}$ (right panel in $A$ ) and by the subsequent demonstration of a low-threshold spike ( $*$, right panel in $B$ ) when the neuron is hyperpolarized from rest in whole-cell recordings $(B) . C, D$, Application of $A C h$ (in the presence of atropine and TTX) results in a short-lasting hyperpolarization ( $C$ ) that is completely abolished by yohimbine, a selective $\alpha 2$ receptor antagonist $(D)$. E, Bath-applied noradrenaline in the presence of TTX also induces a hyperpolarization. Note that it is accompanied by a decrease in membrane resistance, as revealed by comparing (inset) short hyperpolarizing pulses before (filled square) and during (filled dot) the effect. $F$, The noradrenaline-induced hyperpolarization (when the neuron is at rest; $-61 \mathrm{mV})$ is abolished when it is held close to $E_{\mathrm{K}}(-83 \mathrm{mV})$ and reverses below $(-103$ $\mathrm{mV}$ ). $\mathrm{G}$, The ACh-induced hyperpolarization in the presence of atropine is also abolished when the neuron is hold at $-83 \mathrm{mV}$ and reverses below.

left panel) and to ACh by iontophoretic application in the presence of atropine (Fig. $4 A$, right panel). Whole-cell recording was then established (Fig. $4 B$, left panel), revealing that a strong lowthreshold spike, characteristic of the putative sleep-promoting neurons (Gallopin et al., 2000), could also be evoked (Fig. 4B, right panel, asterisk). When these cells were tested for their response to ACh in the presence of atropine and TTX, as seen in 
Figure $4 C$, a short-lasting hyperpolarization was revealed $(n=11$ of 22). As seen previously with the extracellular recordings, the ACh response was always abolished by the addition of yohimbine at $2 \mu \mathrm{M}(n=4$ of 4$)$ (Fig. $4 D)$, thus suggesting that the nicotinic response was mediated by the presynaptic release of NA.

\section{The nicotinic inhibition of VLPO neurons results from activation of a potassium conductance}

Finally, we explored the membrane mechanism underlying the nicotinic-induced hyperpolarization of VLPO neurons. As shown in Figure $4 E$, bath application of NA in the presence of TTX results in a hyperpolarization $(n=12$ of 12$)$ that was always accompanied by a decrease in membrane resistance $(n=8$ of 8$)$. This effect must result from the increase of a potassium conductance because it was abolished when neurons were held at -80 $\mathrm{mV}$, i.e., close to $E_{\mathrm{K}}$ ( $n=7$ of 7 ; data not shown), and actually reversed below $E_{\mathrm{K}}(n=3$ of 3 ) (Fig. $4 F)$. In a similar way, when neurons were tested by iontophoretic application of ACh (in the presence of atropine), the hyperpolarizing response was abolished when the membrane potential was held at $-80 \mathrm{mV}(n=5$ of 5; data not shown) and reversed below $E_{\mathrm{K}}(n=3$ of 3 ; same cells as those tested for NA) (Fig. 4G).

\section{Discussion}

The present results indicate that ACh inhibits putative sleeppromoting neurons in the VLPO through a nicotinic presynaptic action involving the facilitation of NA release together with a muscarinic postsynaptic action. These dual presynaptic and postsynaptic cholinergic actions are synergistic in inhibiting sleep-promoting neurons and thus enhancing the activity of wake-promoting neurons through disinhibition.

Our previous pharmacological study showed that VLPO neurons are inhibited by several neurotransmitters of the arousal systems, including ACh (Gallopin et al., 2000). The present study indicates that the effect originally elicited by the mixed muscarinic-nicotinic agonist carbachol was attributable in large part to a postsynaptic muscarinic inhibition because the effect of ACh is reduced by the antagonist atropine, is mimicked by muscarine, and persists in conditions of synaptic blockade. Although not as common as muscarinic excitation, muscarinic inhibition has been described in many different types of neurons in the brain (McCormick and Pape, 1988; Luebke et al., 1993; Leonard and Llinas, 1994; Pan and Williams, 1994; Khateb et al., 1997). It is noteworthy that the origin of the cholinergic input to the VLPO is still in dispute but could arise from the mesopontine tegmentum (Chou et al., 2002; Schmidt et al., 2003).

Whereas the postsynaptic involvement of muscarinic receptors in the cholinergic inhibition of VLPO neurons was thus not surprising, the involvement of nicotinic receptors in this inhibition was more unexpected. Particularly unforeseen was the robustness of the effect and the identity of the presynaptic elements. The evidence for the nicotinic inhibition of VLPO neurons rests on several arguments, including the inhibitory action of nicotine and the nicotinic agonist epibatidine, the persistence, albeit shortened, of a cholinergic inhibition in presence of atropine, and the blockage of this remaining inhibition by a nicotinic antagonist. Although the precise characterization of the nicotinic receptors involved in this inhibition was beyond the scope of the present study, the effect of the nicotinic agonist epibatidine applied at $10 \mathrm{~nm}$ together with the absence of antagonism of the nicotinic responses by MLA (contrasted by the antagonism by $\mathrm{DH} \beta \mathrm{E}$ ) suggest the presence of nAChRs containing the $\alpha 2, \alpha 3$, or $\alpha 4$ subunits and not $\alpha 7$ subunits (for a recent review, see Raggenbass and Bertrand, 2002).

The persistence of a nicotinic hyperpolarization of VLPO neurons in the presence of TTX and its abolition by either yohimbine or holding the cells at $E_{\mathrm{K}}$ suggest that it results from the release of NA and the subsequent opening of potassium channels. Nicotinic receptors located presynaptically have been shown to modulate the release of numerous transmitters in the brain (Wonnacott, 1997; Jones et al., 1999). In the case of noradrenaline, however, in contrast to glutamate or GABA, previous studies have generally not used an electrophysiological approach that permitted the determination of the postsynaptic effect of the released NA. The one study in which this characterization was undertaken involved putative serotonergic neurons in the dorsal raphe nucleus (Li et al., 1998). In this case, the activation of nicotinic receptors led to a depolarization of serotoninergic neurons attributable to the presynaptic facilitation of noradrenaline release. Because a direct muscarinic action has not been described on these latter cells, it is not known whether a functional complementarity between presynaptic nicotinic and postsynaptic muscarinic receptors, as illustrated in our study, holds true in this case. In fact, previous studies involving putative serotoninergic neurons in the raphe magnus nucleus have pointed to the reverse and actually reported a postsynaptic muscarinic inhibition (Pan and Williams, 1994).

The documented presynaptic and postsynaptic cholinergic together with postsynaptic noradrenergic inhibition of the VLPO neurons supports the notion that these cells would be under inhibitory control by the neurotransmitters released from neurons that are in turn preferentially active during and involved in promoting waking (Gallopin et al., 2000; Jones, 2003). Accordingly, during slow-wave sleep (SWS), when the discharge of neurons of the arousal systems is reduced (Jones, 2003), the overall inhibition of the VLPO would be reduced. However, whereas noradrenergic locus ceruleus neurons are active during waking and silent during rapid eye movement sleep (REMS) (Aston-Jones and Bloom, 1981), cholinergic neurons appear to be active during both waking and REMS (Williams et al., 1994; Marrosu et al., 1995; Vazquez and Baghdoyan, 2001). Assuming that all cholinergic neurons are active during both states, VLPO neurons would be inhibited by ACh during REMS as well as waking and thus be active uniquely during SWS. From in vivo recording studies, it appears that most VLPO neurons discharge at higher rates during sleep than during waking, and, of these, most discharge at higher rates during SWS than during REMS (Szymusiak et al., 1998). Accordingly the cholinergic influence acting synergistically with the noradrenergic, one would serve to inhibit the VLPO discharge maximally during waking but also to a degree in the absence of the noradrenergic influence during REMS.

Finally, the present results indicate that, as a stimulant, nicotine may act by indirectly inhibiting sleep-promoting neurons through presynaptic enhancement of NA release, while also directly exciting neurons of the arousal systems (for review, see Koelega, 1993; Jones, 2000, 2003). This effect could serve during waking to remove any residual inhibitory influence on wakepromoting neurons that may be exerted by the GABAergic VLPO neurons that may discharge at low rates during certain waking conditions (Szymusiak et al., 1998). Accordingly, the indirect inhibitory action of nicotine on sleep-promoting VLPO neurons may represent an important mechanism underlying the promotion of arousal and enhancement of vigilance by nicotine. 


\section{References}

Aston-Jones G, Bloom FE (1981) Activity of norepinephrine-containing locus coeruleus neurons in behaving rats anticipates fluctuations in the sleep-waking cycle. J Neurosci 1:876-886.

Chou TC, Bjorkum AA, Gaus SE, Lu J, Scammell TE, Saper CB (2002) Afferents to the ventrolateral preoptic nucleus. J Neurosci 22:977-990.

Dodt HU, Zieglgansberger W (1994) Infrared videomicroscopy: a new look at neuronal structure and function. Trends Neurosci 17:453-458.

Eggermann E, Gallopin T, Fort P, Luppi P-H, Mühlethaler M, Serafin M (2000) Adenosine decreases presynaptic inhibition of sleep-promoting ventrolateral preoptic neurons in vitro. Soc Neurosci Abstr 26:655.610.

Gallopin T, Fort P, Eggermann E, Cauli B, Luppi PH, Rossier J, Audinat E, Mühlethaler M, Serafin M (2000) Identification of sleep-promoting neurons in vitro. Nature 404:992-995.

Jones BE (2000) Basic mechanisms of sleep-wake state. In: Principles and practice of sleep medicine, Ed 3 (Kryger MH, Roth T, Dement WC, eds), pp 134-154. Philadelphia: Saunders.

Jones BE (2003) Arousal systems. Front Biosci 8:S438-S451.

Jones S, Sudweeks S, Yakel JL (1999) Nicotinic receptors in the brain: correlating physiology with function. Trends Neurosci 22:555-561.

Khateb A, Fort P, Williams S, Serafin M, Jones BE, Muhlethaler M (1997) Modulation of cholinergic nucleus basalis neurons by acetylcholine and $N$-methyl-D-aspartate. Neuroscience 81:47-55.

Koelega HS (1993) Stimulant drugs and vigilance performance: a review. Psychopharmacology 111:1-16.

Leonard CS, Llinas R (1994) Serotonergic and cholinergic inhibition of mesopontine cholinergic neurons controlling REM sleep: an in vitro electrophysiological study. Neuroscience 59:309-330.

Li X, Rainnie DG, McCarley RW, Greene RW (1998) Presynaptic nicotinic receptors facilitate monoaminergic transmission. J Neurosci 18:1904-1912.

Lu J, Greco MA, Shiromani P, Saper CB (2000) Effect of lesions of the ventrolateral preoptic nucleus on NREM and REM sleep. J Neurosci 20:3830-3842.

Lu J, Bjorkum AA, Xu M, Gaus SE, Shiromani PJ, Saper CB (2002) Selective activation of the extended ventrolateral preoptic nucleus during rapid eye movement sleep. J Neurosci 22:4568-4576.

Luebke JI, McCarley RW, Greene RW (1993) Inhibitory action of muscarinic agonists on neurons in the rat laterodorsal tegmental nucleus in vitro. J Neurophysiol 70:2128-2135.

Marrosu F, Portas C, Mascia MS, Casu MA, Fa M, Giagheddu M, Imperato A, Gessa GL (1995) Microdialysis measurement of cortical and hippocam- pal acetylcholine release during sleep-wake cycle in freely moving cats. Brain Res 671:329-332.

McCormick DA, Pape HC (1988) Acetylcholine inhibits identified interneurons in the cat lateral geniculate nucleus. Nature 334:246-248.

McGinty DJ, Sterman MB (1968) Sleep suppression after basal forebrain lesions in the cat. Science 160:1253-1255.

Mignot E, Taheri S, Nishino S (2002) Sleeping with the hypothalamus: emerging therapeutic targets for sleep disorders. Nat Neurosci 5 [Suppl 1]:1071-1075.

Nauta WJH (1946) Hypothalamic regulation of sleep: an experimental study. J Neurophysiol 9:285-316.

Pace-Schott EF, Hobson JA (2002) The neurobiology of sleep: genetics, cellular physiology and subcortical networks. Nat Rev Neurosci 3:591-605.

Pan ZZ, Williams JT (1994) Muscarine hyperpolarizes a subpopulation of neurons by activating an M2 muscarinic receptor in rat nucleus raphe magnus in vitro. J Neurosci 14:1332-1338.

Raggenbass M, Bertrand D (2002) Nicotinic receptors in circuit excitability and epilepsy. J Neurobiol 53:580-589.

Saper CB, Chou TC, Scammell TE (2001) The sleep switch: hypothalamic control of sleep and wakefulness. Trends Neurosci 24:726-731.

Schmidt MH, Gervasoni D, Luppi PH, Fort P (2003) Quantitative analysis of cholinergic afferents to the ventrolateral preoptic area: role in waking mechanisms. Sleep 26:A37.

Sherin JE, Shiromani PJ, McCarley RW, Saper CB (1996) Activation of ventrolateral preoptic neurons during sleep. Science 271:216-219.

Sherin JE, Elmquist JK, Torrealba F, Saper CB (1998) Innervation of histaminergic tuberomammillary neurons by GABAergic and galaninergic neurons in the ventrolateral preoptic nucleus of the rat. J Neurosci 18:4705-4721.

Szymusiak R, Alam N, Steininger TL, McGinty D (1998) Sleep-waking discharge patterns of ventrolateral preoptic/anterior hypothalamic neurons in rats. Brain Res 803:178-188.

Szymusiak R, Steininger T, Alam N, McGinty D (2001) Preoptic area sleepregulating mechanisms. Arch Ital Biol 139:77-92.

Vazquez J, Baghdoyan HA (2001) Basal forebrain acetylcholine release during REM sleep is significantly greater than during waking. Am J Physiol Regul Integr Comp Physiol 280:R598-R601.

Von Economo C (1931) Encephalitis lethargica. Its sequelae and treatment. London: Oxford UP.

Williams JA, Comisarow J, Day J, Fibiger HC, Reiner PB (1994) Statedependent release of acetylcholine in rat thalamus measured by in vivo microdialysis. J Neurosci 14:5236-5242.

Wonnacott S (1997) Presynaptic nicotinic ACh receptors. Trends Neurosci 20:92-98. 